\title{
Ciliary Neurotrophic Factor is a Regulator of Muscular Strength in Aging
}

\author{
Catherine Guillet, ${ }^{1}$ Patrick Auguste, ${ }^{1}$ Willy Mayo, ${ }^{2}$ Paul Kreher, ${ }^{3}$ and Hugues Gascan ${ }^{1}$ \\ 1/nstitut National de la Santé et de la Recherche Médicale (INSERM) CJF 97-08, Centre Hospitalier Universitaire Angers, \\ 49033 Angers Cedex, France, 2INSERM U259, 33077 Bordeaux Cedex, France, and ${ }^{3}$ Laboratoire de Neurophysiologie, \\ Centre National de la Recherche Scientifique-EREA 120, 49045 Angers Cedex, France
}

Ciliary neurotrophic factor (CNTF) participates in the survival of motor neurons and reduces the denervation-induced atrophy of skeletal muscles. Experiments performed in rats show a decrease in peripheral CNTF synthesis during aging, associated with an overexpression of its $\alpha$-binding receptor component by skeletal muscles. Measurement of sciatic nerve CNTF production and of the muscular performance developed by the animals revealed a strong correlation between the two studied parameters $(r=0.8 ; p<0.0003)$. Furthermore, the twitch and tetanic tensions measured in the isolated soleus skeletal muscle in 24-month-old animals increased 2.5 -fold by continuous in vivo administration of CNTF. Analyses of the activation level of leukemia inhibitory factor receptor $\beta$ - and signal transducer and activator of transcription 3-signaling molecules in response to exogenous CNTF revealed an increased tyrosine phosphorylation positively correlated with the twitch tension developed by the soleus muscle of the animals.

Key words: CNTF; CNTFR $\alpha$; aging; muscular strength; LIFR $\beta$; STAT3
Ciliary neurotrophic factor $(\mathrm{CNTF})$ is a protein that promotes the differentiation and survival of a wide range of cell types in the nervous system (Stöckli et al., 1989). CNTF was largely characterized for its ability to sustain the survival of motor neurons in vitro and in vivo (Sendtner et al., 1990, 1997; Oppenheim et al., 1991). Additional studies have shown that CNTF prevents the degeneration of axotomized motor neurons and attenuates the motor deficits in several strains of mice with neuromuscular deficiencies and that adult $\mathrm{CNTF}-/-$ mice display a weak decrease in muscle strength (Sendtner et al., 1992a; Apfel et al., 1993; Curtis et al., 1993; Masu et al., 1993; Mitsumoto et al., 1994). CNTF is abundantly synthesized by Schwann cells in adult peripheral nerves (Friedman et al., 1992; Sendtner et al., 1992b). More recently, the possibility that $\mathrm{CNTF}$ acts as a nerve-derived myotrophic factor was also established (Forger et al., 1993; Helgren et al., 1994; DiStefano et al., 1996).

CNTF uses a multimeric receptor composed of the gp130 signal-transducing protein associated with the leukemia inhibitory factor receptor $\beta(\operatorname{LIFR} \beta)$ component (Hibi et al., 1990; Gearing et al., 1992; Davis et al., 1993a). The CNTF receptor also includes a specific binding subunit known as CNTF receptor $\alpha(\mathrm{CNTFR} \alpha)$, anchored to the membrane through a glycosylphosphatidylinositol linkage (Davis et al., 1991; DeChiara et al., 1995). Association of CNTF to its $\alpha$ receptor component subsequently leads to gp130-LIFR $\beta$ dimerization and signaling activation events (Davis et al., 1993a). Because CNTF cannot

Received Aug. 6, 1998; revised Dec. 2, 1998; accepted Dec. 7, 1998.

This work was supported by a grant from Association Française contre les Myopathies. C.G. was funded by a fellowship from Conseil Général du Maine et Loire and by Comité du Maine et Loire de la Ligue contre le Cancer. We thank Dr. J.F. Leterrier for the initial sciatic nerve samples, and Dr. Bruce Koppelman for his careful reviewing of this manuscript. We also thank J. Froger for her technical assistance and J.P. Gislard for assistance with photography.

Correspondence should be addressed to Hugues Gascan, Institut National de la Santé et de la Recherche Médicale CJF 97-08, 4 rue Larrey, Centre Hospitalier Universitaire Angers, 49033 Angers Cedex, France.

Copyright (C) 1999 Society for Neuroscience $\quad 0270-6474 / 99 / 191257-06 \$ 05.00 / 0$ directly activate its $\beta$ receptor components in the absence of CNTFR $\alpha$, expression and tissue distribution of CNTFR $\alpha$ subunit largely govern CNTF responses (Davis et al., 1993b). CNTFR $\alpha$ exhibits widespread localization in the developing nervous system of the embryo and in the adult brain (Ip et al., 1993; McLennan et al., 1994). In addition to its nervous system distribution, CNTFR $\alpha$ and its associated signaling receptors gp130 and LIFR $\beta$ are also abundantly expressed by skeletal muscles (DeChiara et al., 1995; Ip et al., 1993). After denervation, the expression of CNTF receptor components are rapidly increased in mammalian muscles (Helgren et al., 1994). Furthermore, exogenous administration of CNTF partially rescues denervationinduced muscular atrophy and attenuates the reduced twitch and tetanic tensions observed in these conditions (Helgren et al., 1994). Age-related impairment of motor capacity has been linked to several deleterious morphological and functional changes involving neuromuscular interactions (Jacob and Robbins, 1990; Faulkner and Brooks, 1995), however the causal factors responsible for these changes are poorly understood.

\section{MATERIALS AND METHODS}

Protein analysis. Sciatic nerves or soleus muscles from adult (6 months) and aged (24 months) male animals were mechanically disrupted in PBS containing $0.1 \mathrm{~mm}$ PMSF. The tissue extracts were obtained after two 15 min centrifugations at $100,000 \times g$. After protein determination, CNTF content in sciatic extracts was determined by ELISA. ELISA plates were coated with a rabbit anti-rat CNTF polyclonal antibody generated in the laboratory. After washing and a saturation step, the samples were incubated overnight at $4^{\circ} \mathrm{C}$. The $5 / 3 / 6 \mathrm{~B}$ anti-CNTF monoclonal antibody (Boehringer Mannheim, Mannheim, Germany) was used as tracer antibody and added to the wells for $5 \mathrm{hr}$ at $37^{\circ} \mathrm{C}$. The detection was achieved by using a goat anti-mouse polyclonal antibody conjugated to horseradish peroxidase (Biosource, Camarillo, CA). Sensitivity of the ELISA was 40 $\mathrm{pg} / \mathrm{ml}$. Gp130 detection in soleus muscle extracts was determined by ELISA as well, with a goat anti-gp130 polyclonal antibody (R \& D Systems, Minneapolis, MN) as coating antibody and the previously described B-K11 anti-gp130 monoclonal antibody as tracer (Chevalier et al., 1996). For LIFR $\beta$ determination and signal transducer and activator 
of transcription 3 (STAT3) analyses, the soleus muscles were homogenized in the presence of 1\% Brij 96 detergent in lysis buffer (Chevalier et al., 1996). After protein standardization, samples were immunoprecipitated with an anti-LIFR $\beta$ polyclonal antibody (Santa Cruz Biotechnology, Santa Cruz, CA) or with the 4G10 anti-phosphotyrosine monoclonal antibody (Upstate biotechnology, Lake Placid, NY). The proteins were then separated by SDS-PAGE and immunoblotted by using the same anti-LIFR $\beta$ antibody (Chevalier et al., 1996) or an anti-STAT3 monoclonal antibody from Transduction Laboratories (Lexington, KY). After film exposure, obtained signals were quantified by laser densitometry.

Northern blot analysis. Northern blots were performed using a rat CNTF cDNA probe, a rat CNTFR $\alpha$ cDNA probe, or a cDNA encoding for GAPDH as previously described (Robledo et al., 1996), except that the hybridizations were performed in the presence of Quikhyb solution from Stratagene (La Jolla, CA).

Determination of swimming speed. The swimming performance of the animals was evaluated in a circular swimming pool adapted from the spatial memory task of Morris (1984) and computed by a video tracking system (Videotrack 512; Viewpoint, Lyon, France). Rats were gently put in the water $\left(22^{\circ} \mathrm{C}\right)$ and left to swim for $90 \mathrm{sec}$. Four nonconsecutive trials were done each day for $3 \mathrm{~d}$.

CNTF treatment and muscle physiology. Rat CNTF was produced as a GST fusion protein by using the pGEX-4T2 gene fusion vector from Pharmacia (Uppsala, Sweden) before being cleaved with thrombin and further purified by a reverse-phase HPLC step. Sterile filtered CNTF diluted in PBS or PBS alone were administered for $14 \mathrm{~d}$ at a flow rate of $16 \mu \mathrm{g} \cdot \mathrm{kg}^{-1} \cdot \mathrm{hr}^{-1}$ from a mini-osmotic pump (model 2002; Alza, Palo Alto, CA) implanted subcutaneously in the right hindlimb of male animals. Osmotic pump flow delivery, stability, and bioactivity of CNTF were monitored in vitro by ELISA determination and TF1 cell bioassay as described previously (Chevalier et al., 1996). Treated and control rats were anesthesized with pentobarbital sodium, and soleus muscles were rapidly removed, placed in an aerated $\left(95 \% \mathrm{O}_{2}\right.$ and $\left.5 \% \mathrm{CO}_{2}\right)$ Ringer's solution at $22^{\circ} \mathrm{C}$, and attached to a force transducer. Muscles were directly stimulated with two silver electrodes. An optimal length-tension relationship was established, and the preparation was allowed to equilibrate (Witzmann et al., 1982; Helgren et al., 1994). Maximal twitch tension was recorded after a supramaximal $0.5 \mathrm{msec}$ square wave pulse. Peak tetanic tension was determined after a $300 \mathrm{msec}$ train of a supramaximal stimulus at a frequency of $150 \mathrm{~Hz}$. After contraction experiments, the soleus muscles from CNTF and saline-treated animals were frozen in isopentane before being cut in $5 \mu \mathrm{m}$ cross sections. The slides were stained for acetylcholinesterase using 5-bromoindoxyl acetate, and the fibers were visualized under the microscope and photographed. For each group, cross-sectional pictures from 200 fibers were carefully and individually cut and weighed. The fiber areas were calculated from the picture paper weight and the magnification of the microscope represented by a size bar on the pictures. Specific pathogen-free animals used in the present study were bought from Charles River (Saint-Aubin-lèsElbeuf, France) and immediately used in the experiments. All the animal experiments were performed in accordance with the French state legislation.

\section{RESULTS}

\section{Regulation of CNTF and its $\alpha$ receptor component in aging}

CNTF expression in sciatic nerves was analyzed as an indicator of its peripheral synthesis in 6- and 24-month-old rats. Initial experiments were performed in several rat strains, and despite some variations observed in the average production of CNTF between the studied strains, a twofold to fourfold decrease in CNTF expression was consistently observed in aged animals compared with younger adult animals (Fig. 1A). To determine whether the observed variation in CNTF content was caused by a decrease in CNTF production or in the protein stability, the regulation of CNTF transcription in young adult and aged Sprague Dawley rats was examined. A decrease in the expression of CNTF transcripts was observed in 24-month-old animals (Fig.
A
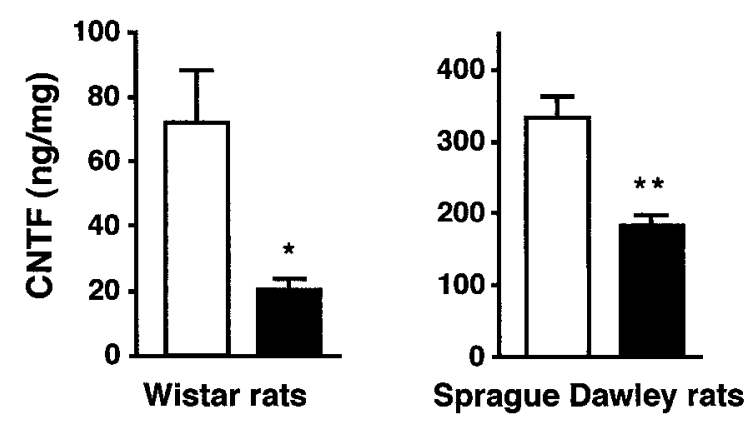

B

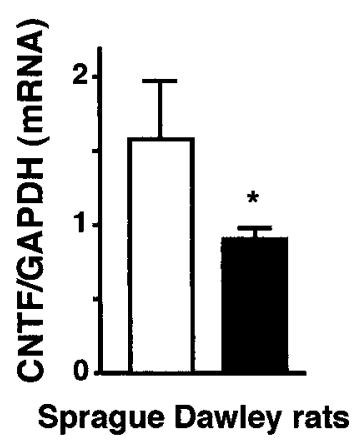

Figure 1. CNTF expression in sciatic nerve of adult (6 months) and aged (24 months) rats. $A$, ELISA detection of CNTF in sciatic nerve extracts from two different strains of rats. The results are expressed in nanograms per milligram of total protein. Values are mean \pm SEM. Left, Adult rats, $n=4$; aged rats, $n=3$; * $p<0.05$; Student's $t$ test. Right, Adult rats, $n=$ 7 ; aged rats, $n=8$; ** $p<0.001$; Student's $t$ test. $B$, CNTF and GAPDH mRNA levels in sciatic nerves from male Sprague Dawley rats were determined by Northern blot and quantified by laser densitometry. Adult rats, $n=3$; aged rats, $n=8$; *p $<0.05$; Student's $t$ test. Values are mean \pm SEM.

1B). Reduced CNTF mRNA and protein expression in aged rats compared with young adult rats indicates a transcriptional regulation of CNTF in aging.

To examine the expression of CNTFR $\alpha$ in adult and aged animals, Northern blot analysis was performed on RNA extracted from various sciatic nerve target muscles including the soleus, the extensor digitorum longus (EDL), the gastrocnemius, and the tibialis posterior muscles. CNTFR $\alpha$ expression was readily apparent in all muscle types examined, and interestingly, its mRNA expression increased 10- to 20-fold between 12- and 24-month-old animals (Fig. $2 A$ ). Representativeness of the observed phenomenon was further assessed by analyzing the CNTFR $\alpha$ expression on a group of six young adult and seven aged animals. Analyses performed on the soleus muscle strongly reinforced the kinetic observations and indicate that the observed elevation in CNTFR $\alpha$ in skeletal muscles was a general phenomenon in aging population (Fig. 2B). In a third set of experiments, levels of proteins for the two other components of the functional CNTF receptor complex, gp130 and LIFR $\beta$, were studied. LIFR $\beta$ and gp130 were also readily detectable, but their expression levels remained unchanged in aged and adult animals (Fig. 2C). These results indicate a specific regulation of CNTF and of its $\alpha$ receptor subunit during aging. 
A

soleus EDL gastroc. tib.post.

$\overline{36121824} \overline{36121824} \overline{36121824} \overline{36121824}$ (months)

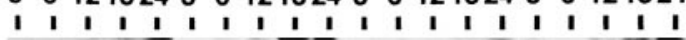

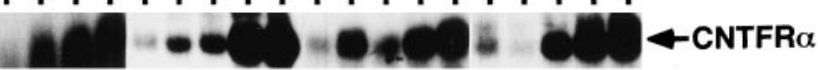

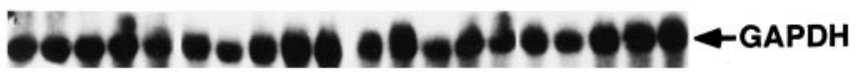

B

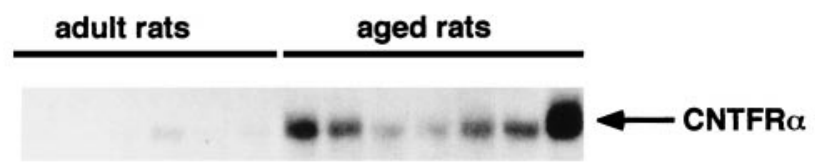

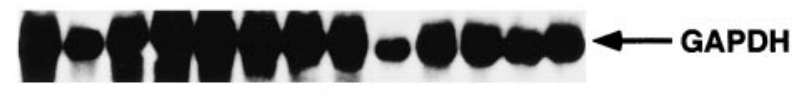

C
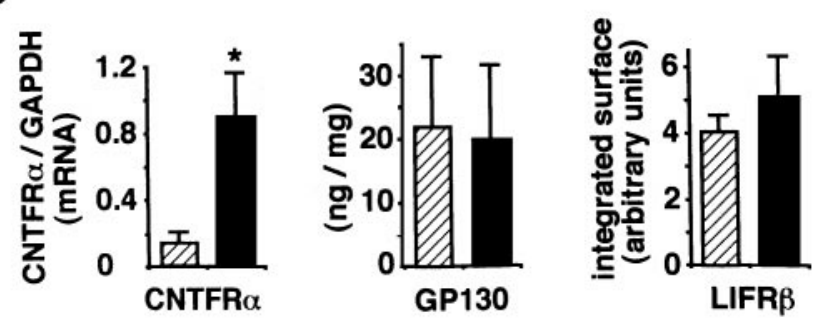

Figure 2. Regulation of CNTF receptor components in skeletal muscles during aging. $A$, Expression of CNTFR $\alpha$ mRNA in different hindlimb muscles. Experiments were performed in the soleus, extensor digitorum longus (EDL), gastrocnemius (gastroc.), and tibialis posterior (tib.post.) muscles of male Sprague Dawley rats aged of 3, 6, 12, 18, and 24 months. $B, \mathrm{CNTFR} \alpha$ mRNA expression in the soleus muscles from six adult ( 6 months) and seven aged (24 months) male Sprague Dawley rats. CNTFR $\alpha$ mRNA was also readily detectable in soleus muscle from adult rats after a longer exposure time, as shown in $A$. $C$, Expression of CNTF receptor subunits in the soleus muscle from adult (hatched bars) and aged (black bars) male Sprague Dawley rats. CNTFR $\alpha$ expression detected in the soleus muscle by Northern blot analysis was quantified by laser densitometry, and the obtained values were presented as a CNTFR $\alpha$ / GAPDH ratio. Gp130 content was determined in the same muscles by ELISA detection after total protein content determination, and the results were expressed in nanograms per milligram of protein. LIFR $\beta$ determination was achieved by immunoprecipitation and Western blotting, and the signals were quantified by laser densitometry. Adult rats, $n=6$; aged rats, $n=7 ;{ }^{*} p<0.0001$; Student's $t$ test. Values are mean \pm SEM.

\section{Evidence for a strong correlation between muscle strength developed by the animals and sciatic CNTF synthesis}

We have further analyzed the relationship between CNTF synthesis and the skeletal muscle response by measuring in adult and aged animals both peripheral CNTF production and their functional performance. To assess a global image of whole animal muscular activity, an analysis of its average swimming speed was recorded in a swimming pool by using a video tracking system (Morris, 1984). CNTF concentration, as determined by ELISA, and average swimming speed measurements revealed a strong correlation between these two parameters $(r=0.8 ; p<0.0003)$ (Fig. 3). These results indicate that either CNTF production and muscular strength developed by the animals are coregulated through a common mechanism present throughout the life of the animals or that CNTF interaction with its receptor complex

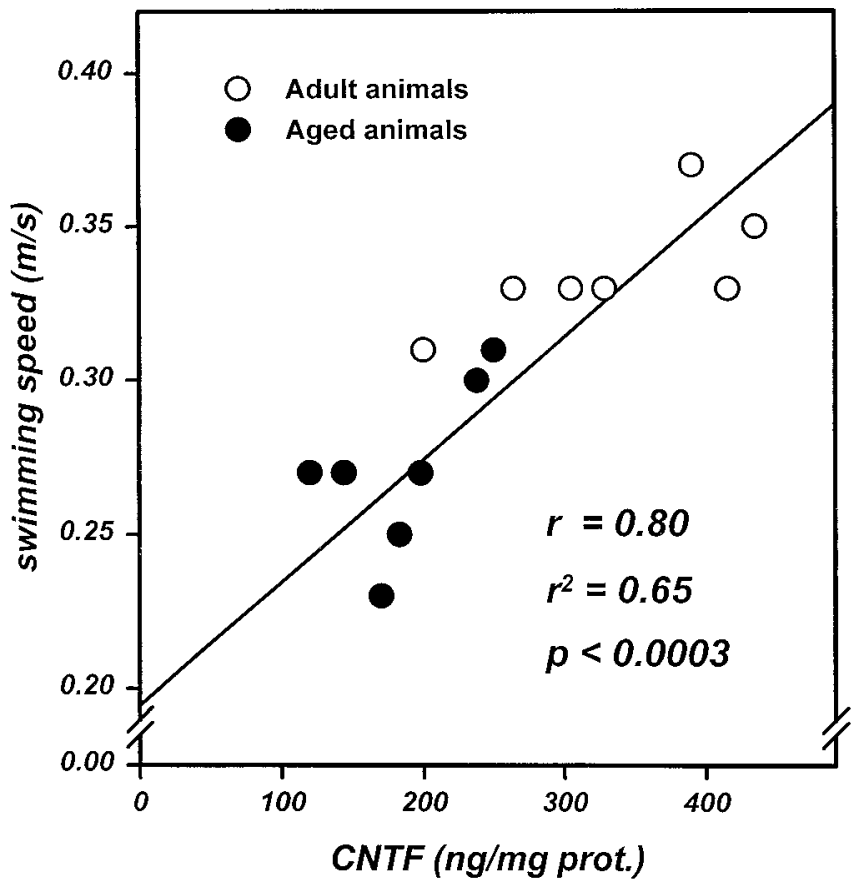

Figure 3. Swimming speed as a function of CNTF content in the sciatic nerve. Swimming speed was determined as described in detail in Materials and Methods and sciatic CNTF content was monitored by ELISA. A positive correlation between the two parameters was observed, $r=0.80$; $p<0.0003$.

expressed on the skeletal muscles more directly controls the muscular performances of the animals. To answer this question, animals were treated with subcutaneous administration of CNTF, and their functional response was studied. A previous study indicated that CNTF did not noticeably enhance performance of innervated muscles in 1-3-month-old rats (Helgren et al., 1994), and only aged animals were treated. The cytokine was slowly delivered by using an osmotic pump implanted under the right hindlimb skin of the animal. A low CNTF plasma concentration of $1370 \pm 1082 \mathrm{pg} / \mathrm{ml}$ was detected during the treatment. After a $14 \mathrm{~d}$ treatment no significant variation in the weight was observed between nontreated or saline-treated and CNTFtreated animals ( $p=0.55$ and $p=0.12$, respectively; Student's $t$ test) (Fig. 4), indicating that subcutaneous delivery of CNTF under these conditions did not affect the general metabolism of the animals in a noticeable way.

To evaluate muscle strength, the aged rats were submitted to a swimming test as described above after the administration of a $14 \mathrm{~d}$ CNTF or saline treatment. No significant difference was observed between the mean swimming speed of CNTF or salinetreated animals ( $p=0.14$; Student's $t$ test). Considering that CNTF could act locally at the site of the pump implantation, we assessed the muscular capacity by directly studying the contractile properties of the soleus muscle after treatment. Twitch tension was observed in response to a single electric stimulus, whereas tetanic tension was the force generated in response to highfrequency supramaximal pulses. The values for twitch tension of isolated soleus muscle in vehicle-treated aged animals were similar to that of nontreated aged animals and were $\sim 50 \%$ lower than that in adults of 6 months of age (Fig. $5 A$ ). When treated with CNTF, the twitch tension in aged animals was improved by 


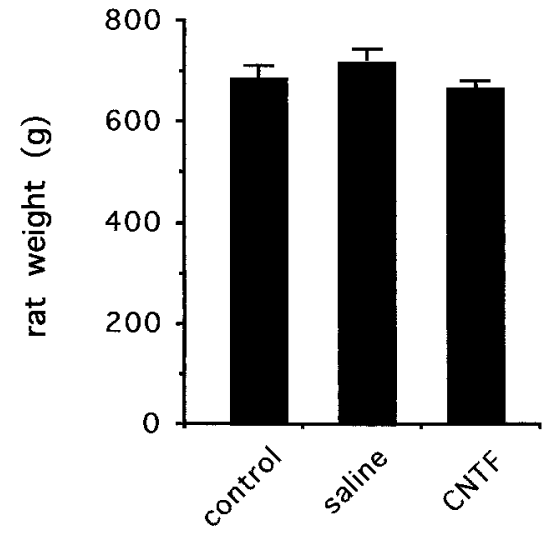

Figure 4. Effect of CNTF treatment on rat weight. Control aged rats, $n=4$; saline-treated animals, $n=4$; CNTF-treated animals, $n=6$. No significant variation of rat weight is observed between control or salinetreated and CNTF-treated rats; $p=0.55$ and $p=0.12$, respectively (Student's $t$ test). Values are mean \pm SEM.
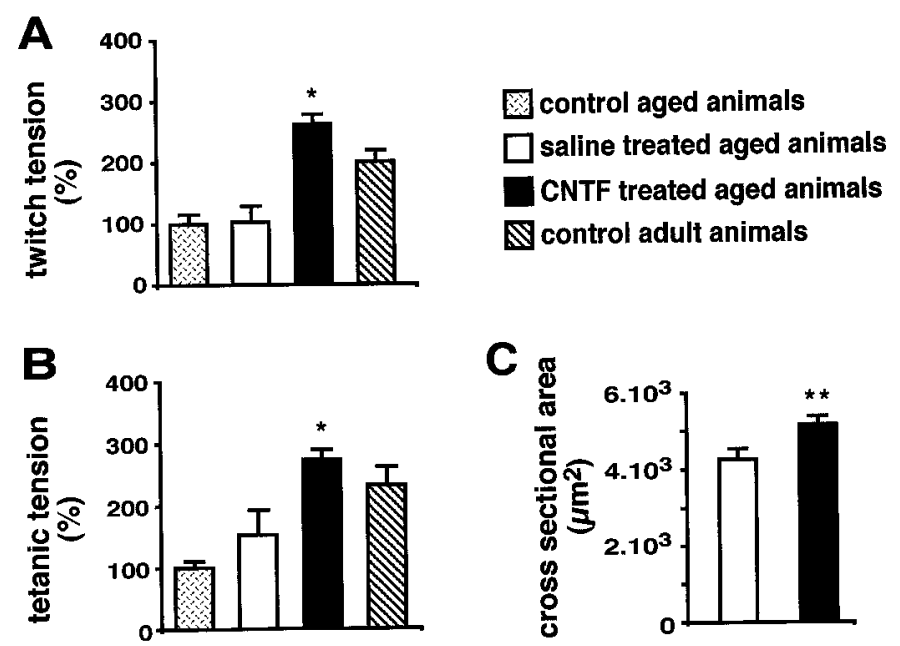

Figure 5. Effect of CNTF treatment on physiological properties of soleus muscle. Twitch tension $(A)$ and tetanic tension $(B)$ were determined after electrical stimulation of the isolated muscles after treatment, as described in Materials and Methods. The forces are expressed in percentage (tensions in millinewtons per milligram of muscle wet weight), and the control aged group values defined the $100 \%$ reference. Control aged animals of 24 months, $n=4$; saline-treated aged animals, $n=4$; CNTF-treated aged animals, $n=6$; control adult rats of 6 months, $n=5$. Values are mean \pm SEM. * $p<0.001$; different from saline-treated animals, Student's $t$ test. $C$, Effect of CNTF treatment on cross-sectional area of soleus muscle fibers in aged animals. ${ }^{* *} p<0.05$; different from saline-treated animals; Student's $t$ test. Values are mean \pm SEM.

2.5-fold (Student's $t$ test; $p<0.001$ ) (Fig. 5A). This enhancement of muscle strength in CNTF-treated animals was also apparent for the tetanic isometric tension determinations when compared with control groups $(p<0.01$ for the CNTF- vs saline-treated group) (Fig. $5 B$ ). The obtained values for the contralateral muscle were not significantly different between the vehicle- and CNTFtreated animals (Student's $t$ test; twitch tension, $p=0.09$; tetanic tension, $p=0.3$ ), indicating that CNTF mainly improved the contractile properties of skeletal muscles at the site of the treatment that corroborates the obtained results in the swimming test.

Several reports show that neurotrophins and cytokines, includ-

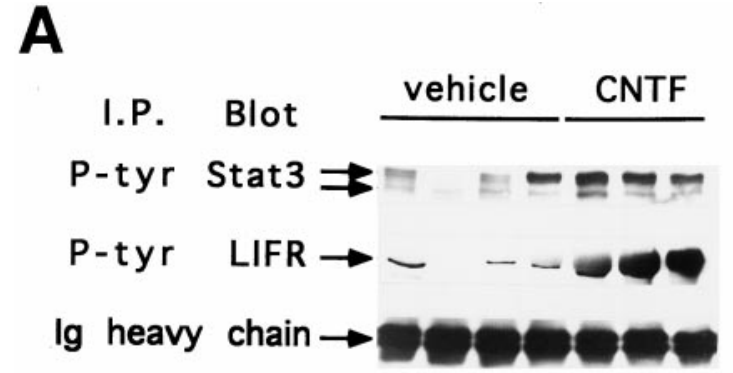

B
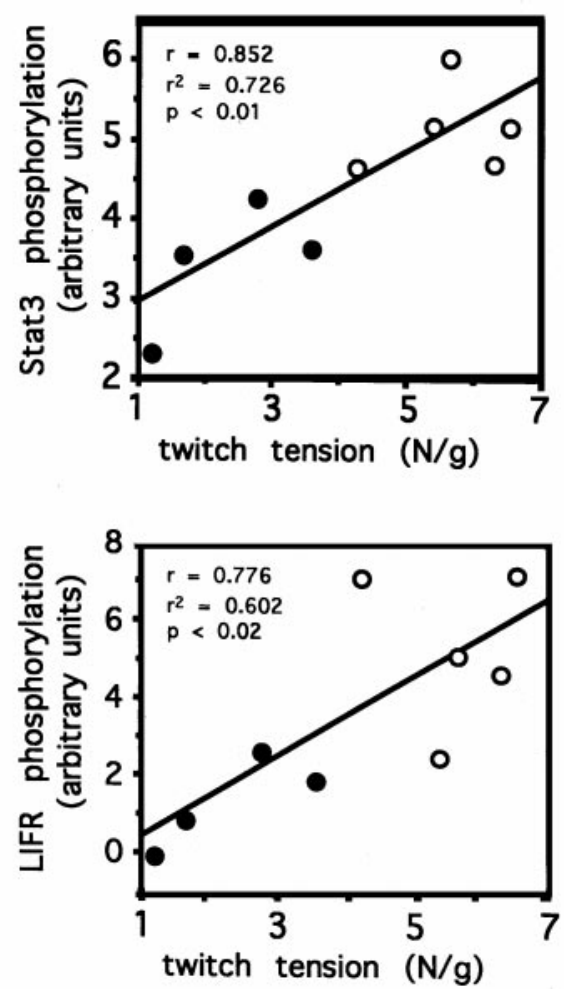

Figure 6. Activation of STAT3 and LIFR $\beta$ after CNTF treatment. $A$, Equal amounts of tissue extracts from soleus muscle treated with CNTF or vehicle were immunoprecipitated with an anti-phosphotyrosine monoclonal antibody. Samples were then submitted to SDS-PAGE and Western-blotted onto a membrane. Phosphorylation level of two STAT3 isoforms and LIFR $\beta$ were determined by staining the membranes with an anti-STAT3 monoclonal antibody and an anti-LIFR $\beta$ polyclonal antibody, respectively. $B, C$, STAT3 and LIFR $\beta$ phosphorylation as a function of the twitch tension developed by saline-treated (closed circles) or CNTFtreated (open circles) aged rats. Signals from the blots $(A)$ were quantified by laser densitometry and expressed in arbitrary units. Twitch tension is expressed in newtons per gram of soleus wet muscle. For each panel, a positive correlation between the two parameters was observed; $r=0.852$, $p<0.01$ and $r=0.776, p<0.02$ for STAT3 and LIFR $\beta$ phosphorylation, respectively.

ing CNTF, could modulate the potentiation of neuromuscular synapses and transmitter release (Stoop and Poo, 1995). In the present study, twitch and tetanic tension measurements were performed by direct electric stimulation of the soleus muscle, indicating that a sensitization of the synaptic transmission was not a requirement to record the obtained responses. Morphological studies were performed, and the cross-sectional areas of muscular fibers in saline- and CNTF-treated muscles in aged animals were determined. After a 14 d CNTF treatment, a significant myotro- 
phic effect of the cytokine on cross-sectional areas of fibers was observed corresponding to a $17.3 \%$ increase of their surface (Student's $t$ test; $p<0.05$ ) (Fig. 5C). The obtained values support the idea of a direct effect of CNTF on the twitch fibers and their contractile properties in aged animals.

\section{CNTF treatment activates signaling mechanisms in muscle}

To assess this hypothesis, we evaluated the activation level of STAT3, a major transcriptional factor involved in the CNTF response (Stahl et al., 1995). Analyses were performed on soleus muscle after CNTF or saline treatment. A noticeable increase in STAT3 tyrosine phosphorylation was observed in CNTF-treated animals (Fig. 6A) that strongly correlates with the twitch tension measurements $(r=0.852 ; p<0.01)$ (Fig. $6 B)$. Specificity of STAT3-mediated signaling was reinforced by analyzing the tyrosine phosphorylation of LIFR $\beta$ on the same muscles. Similar to the results observed for STAT3, an increased activation of the LIFR $\beta$ linked to the twitch tension developed by the soleus muscle was detected after CNTF treatment $(r=0.772 ; p<0.02)$ (Fig. 6C). Altogether, these results demonstrate that CNTF directly exerts its action on muscle tissue by activating its receptor complex and the associated intracellular mechanisms of signaling.

\section{DISCUSSION}

We have observed that CNTF expression level decreases with the senescence of the animal. In the muscle, expression of the $\alpha$ receptor component increases dramatically from 12 to 24 months of age. It is noteworthy that CNTF level is well correlated with muscle strength and that these two parameters decrease with age. When aged animals are treated with exogenous CNTF, muscle strength comes back to that detected in adult rats, demonstrating that CNTF can be an important factor for the maintenance of muscle integrity in noninjured aged animals. Overexpression of CNTFR $\alpha$ in the muscles of aged animals might be involved in a compensatory phenomenon to maintain a CNTF response similar to that present in adult animals. Only a mild loss of motor neurons leading to a minor muscle weakness was observed in CNTF-/- adult mice (Masu et al., 1993). In contrast, the CNTFR $\alpha$ moiety is essential for motor neuron survival during development, and mice harboring an homozygous CNTFR $\alpha$ null mutation shortly die after birth (DeChiara et al., 1995). In line with our observations, we can hypothesize that $\mathrm{CNTF}-/-$ mice could display a more pronounced muscle strength deficiency when they will become aged, suggesting that the phenotype observed in CNTF gene inactivation might reflect a premature muscle aging of these animals.

CNTF was shown to prevent lesion-mediated degeneration of motor neurons (Sendtner et al., 1990, 1997) and to reduce denervation-induced atrophy of skeletal muscle (Helgren et al., 1994). It also displays protective effects in several animal models of neurodegenerative diseases (Sendtner et al., 1992a; Mitsumoto et al., 1994). The present study shows that in normal aged animals that display a reduced muscular activity, CNTF can partially attenuate the functional skeletal muscle modifications. These overall observations tend to ascribe to CNTF a more general role of rescue factor in response to a suffering state of the neuromuscular axis observed in various situations.

\section{REFERENCES}

Apfel SC, Arezzo JC, Moran M, Kessler JA (1993) Effects of administration of ciliary neurotrophic factor on normal motor and sensory peripheral nerves in vivo. Brain Res 604:1-6.
Chevalier S, Fourcin M, Robledo O, Wijdenes J, Pouplard-Barthelaix A, Gascan H (1996) Interleukin-6 family of cytokines induced activation of different functional sites expressed by gp130 transducing protein. J Biol Chem 271:14764-14772.

Curtis R, Adryan KM, Zhu Y, Harkness PJ, Lindsay RM, DiStefano PS (1993) Retrograde axonal transport of ciliary neurotrophic factor is increased by peripheral nerve injury. Nature 365:253-255.

Davis S, Aldrich TH, Valenzuela DM, Wong V, Furth ME, Squinto SP, Yancopoulos GD (1991) The receptor for ciliary neurotrophic factor. Science 253:59-63.

Davis S, Aldrich TH, Stahl N, Pan L, Taga T, Kishimoto T, Ip NY, Yancopoulos GD (1993a) LIFR $\beta$ and gp130 as hetero-dimerizing signal transducers of the tripartite CNTF receptor. Science 260:1805-1808.

Davis S, Aldrich TH, Ip NY, Stahl N, Scherer S, Farruggella T, DiStefano PS, Curtis R, Panayotatos N, Gascan H, Chevalier S, Yancopoulos GD (1993b) Released form of CNTF receptor $\alpha$ component as a soluble mediator of CNTF responses. Science 259:1736-1739.

DeChiara TM, Vejsada R, Poueymirou WT, Acheson A, Suri C, Conover JC, Friedman B, McClain J, Pan L, Stahl N, Ip NY, Kato A, Yancopoulos GD (1995) Mice lacking the CNTF receptor, unlike mice lacking CNTF, exhibit profound motor neuron deficits at birth. Cell 83:313-322.

DiStefano PS, Boulton TG, Stark JL, Zhu Y, Adryan K M, Ryan TE Lindsay RM (1996) Ciliary neurotrophic factor induces downregulation of its receptor and desensitization of signal transduction pathways in vivo. J Biol Chem 271:22839-22846.

Faulkner JA, Brooks SV (1995) Muscle fatigue in old animals. Adv Exp Med Biol 384:471-480.

Forger NG, Roberts SL, Wong V, Breedlove SM (1993) Ciliary neurotrophic factor maintains motoneurons and their target muscles in developing rats. J Neurosci 13:4720-4726.

Friedman B, Scherer SS, Rudge JS, Helgren M, Morrisey D, McClain J, Wang D-Y, Wiegand SJ, Furth ME, Lindsay RM, Ip NY (1992) Regulation of CNTF expression in myelin-related Schwann cells in vivo. Neuron 9:295-305.

Gearing DP, Comeau MR, Friend DJ, Gimpel SD, Thut CJ, McGourty J, Brasher KK, King JA, Gillis S, Mosley B, Ziegler SF, Cosman D (1992) The IL-6 signal transducer, gp130: an oncostatin M receptor and affinity converter for the LIF receptor. Science 255:1434-1437.

Helgren ME, Squinto SP, Davis HL, Parry DJ, Boulton TG, Heck CS, Zhu Y, Yancopoulos GD, Lindsay RM, DiStefano PS (1994) Trophic effect of ciliary neurotrophic factor on denervated skeletal muscle. Cell 76:493-504.

Hibi M, Murakami M, Saito M, Hirano T, Taga T, Kishimoto T (1990) Molecular cloning and expression of an IL-6 signal transducer, gp130. Cell 63:1149-1157.

Ip NY, McClain J, Barrezueta NX, Aldrich TH, Pan L, Li Y, Wiegand SJ, Friedman B, Davis S Yancopoulos GD (1993) The $\alpha$ component of the CNTF receptor is required for signaling and defines potential CNTF targets in the adult and during development. Neuron 10:89-102.

Jacob JM, Robbins N (1990) Differential effects of age on neuromuscular transmission in partially denervated mouse muscle. J Neurosci 10:1522-1529.

Masu Y, Wolf E, Holtmann B, Sendtner M, Brem G, Thoenen H (1993) Disruption of the CNTF gene results in motor neuron degeneration. Nature 365:27-32.

McLennan AJ, Gaskin AA, Lado DC (1994) CNTF receptor alpha mRNA expression in rodent cell lines and developing rat. Mol Brain Res 25:251-256.

Mitsumoto H, Ikeda K, Klinkosz B, Cedarbaumm JM, Wong V, Lindsay RM (1994) Arrest of motor neuron disease in wobbler mice cotreated with CNTF and BDNF. Science 265:1107-1110.

Morris RGM (1984) Developments of a water-maze procedure for studying spatial learning in the rat. J Neurosci Methods 11:47-60.

Oppenheim RW, Prevette D, Qin-Wei Y, Collins F, McDonald J (1991) Control of embryonic motoneuron survival in vivo by ciliary neurotrophic factor. Science 251:1616-1618.

Robledo O, Auguste P, Coupey L, Praloran V, Chevalier S, PouplardBarthelaix A, Gascan H (1996) Binding interactions of leukemia inhibitory factor and ciliary neurotrophic factor with the different subunits of their high affinity receptors. J Neurochem 66:1391-1399.

Sendtner M, Kreutzberg GW, Thoenen H (1990) Ciliary neurotrophic 
factor prevents the degeneration of motor neurons after axotomy. Nature 345:440-441.

Sendtner M, Schmalbruch H, Stöckli KA, Carroll P, Kreutzberg GW, Thoenen H (1992a) Ciliary neurotrophic factor prevents degeneration of motor neurons in mouse mutant progressive motor neuronopathy. Nature 358:502-504.

Sendtner M, Stöckli KA, Thoenen H (1992b) Synthesis and localisation of ciliary neurotrophic factor in the sciatic nerve of the adult rat after lesion and during regeneration. J Cell Biol 118:139-148.

Sendtner M, Götz R, Holtmann B, Thoenen H (1997) Endogenous ciliary neurotrophic factor is a lesion factor for axotomized motoneurons in adult mice. J Neurosci 17:6999-7006.
Stahl N, Farrugella TJ, Boulton TG, Zhong Z, Darnell JE, Yancopoulos GD (1995) Choice of STATs and other substrates specified by modular tyrosine-based motifs in cytokine receptors. Science 267:1349-1353.

Stöckli KA, Lottspeich F, Sendtner M, Masiakowski P, Carroll P, Götz R, Lindholm D, Thoenen H (1989) Molecular cloning, expression, and regional distribution of rat ciliary neurotrophic factor. Nature 342:920-923.

Stoop R, Poo M-M (1995) Potentiation of transmitter release by ciliary neurotrophic factor requires somatic signaling. Science 267:695-699.

Witzmann FA, Kim DH, Fitts RH (1982) Hindlimb immobilization: length-tension and contractile properties of skeletal muscle. J Appl Physiol 53:335-345. 